\title{
PERSPECTIVA TOPOLÓGICA DE LA INCLUSIÓN EN LA EDUCACIÓN SUPERIOR
}

\author{
Herwin Eduardo Cardona Quitián \\ Magister en Psicoanálisis, Subjetividad y Cultura \\ Universidad de Cundinamarca \\ Colombia \\ jonasdorado@hotmail.com
}

Cómo citar este artículo

Cardona, H.E. (2013) Perspectiva topológica de la inclusión en la Educación Superior. Espiral, Revista de Docencia e Investigación. 3 (2)

\begin{abstract}
Resumen
¿Por qué abordar la inclusión desde una perspectiva topológica? El discurso de la inclusión nos presenta, en primera instancia un cambio aparente en la concepción de la diferencia, pero al observarlo en detalle, lo que encontramos es que las implicaciones de la inclusión se fundan en una lógica estructural que implica la exclusión. Podría decirse que inclusión y exclusión son indisociables. Por lo tanto, cuando abordamos problemas como los de la inclusión en la educación superior, es necesario comprender la lógica implícita de la inclusión; su comportamiento topológico y los efectos sobre la diferencia. Este recorrido presenta un análisis de la inclusión desde la topología a partir de diferentes vértices: La lógica de Pierce, el concepto de Homo Sacer, y la teoría del capital humano.
\end{abstract}

Palabras clave: topología, inclusión, exclusión, diferencia, universidad.

\begin{abstract}
But why address inclusion topological perspective? The inclusion discourse presents, in the first instance an apparent change in the conception of the difference, but to observe in detail, what we find is that the implications of the inclusion is based on a structural logic in the exclusion. Arguably, inclusion and exclusion are inseparable. Therefore, when we address issues such as inclusion in higher education, it is necessary to understand the underlying logic of inclusion. The topological behavior and the effects on the difference. This course presents an analysis of the inclusion from the topology from different vertices: Pierce's logic, the concept of Homo Sacer, and human capital theory.
\end{abstract}

Keywords: topology, inclusion, exclusion, difference, university.

\section{Introducción}

La topología es una rama de las matemáticas que estudia las propiedades de los cuerpos geométricos que permanecen inalteradas, aun cuando sufran transformaciones continuas. Por esa razón puede decirse que la topología permite un estudio estructural.

La necesidad de un estudio estructural en las ciencias sociales es urgente por varias razones pero una en especial: las constantes transformaciones de los fenómenos sociales, llevan a suponer que esta esfera sufre modificaciones estructurales. En realidad lo que ocurre es todo lo contrario, aún cuando existen continuas transformaciones en la esfera social, sus propiedades fundamentales permanecen inalteradas. Observar esas propiedades, comprender aquello invariante de la esfera social es realizar un abordaje topológico del fenómeno.

Podemos concluir que este es un abordaje novedoso de la investigación social, pero existe todo un movimiento en las ciencias sociales y en la filosofía, que ha dado ese giro hace tiempo. Parte de ello es lo que conocemos como el giro lingüístico en la filosofía desde finales del siglo XIX. ¿De qué se trata? De la influencia que tendrá la lingüística en el análisis social, permeando disciplinas como la antropología, la filosofía, la sociología y el psicoanálisis. 


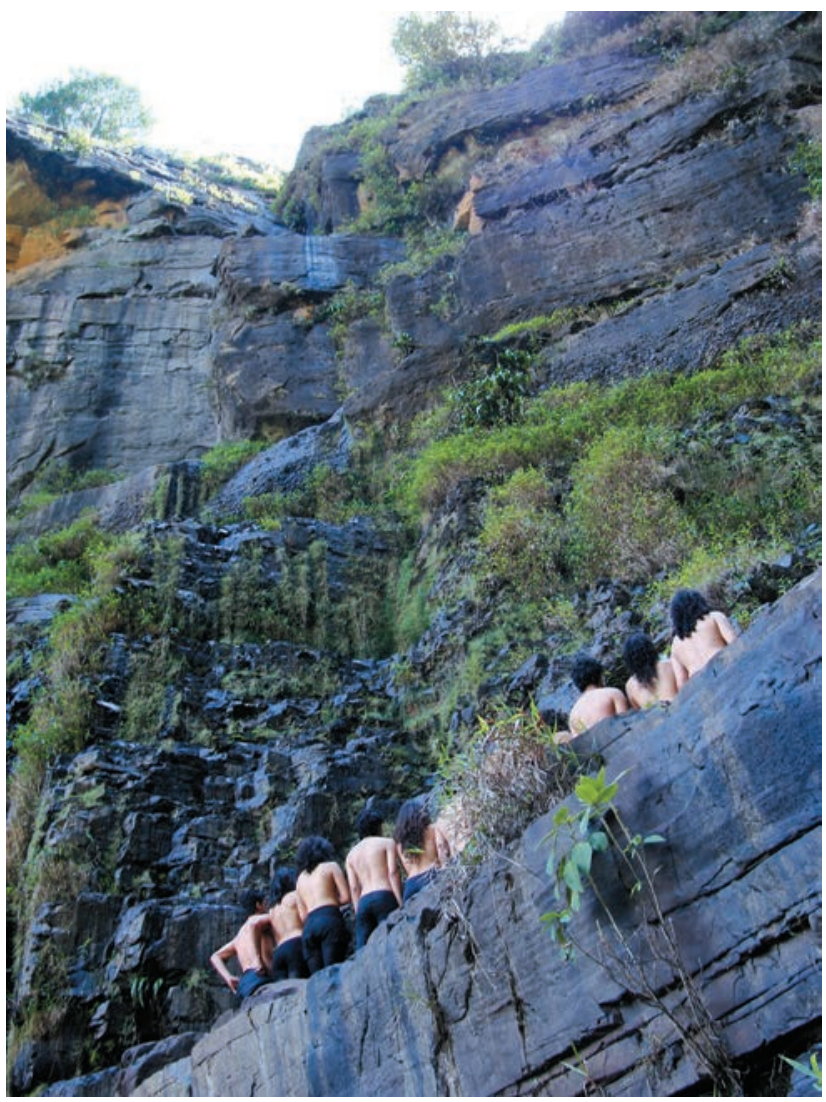

Ahora bien, ¿por qué abordar la inclusión desde una perspectiva topológica? El discurso de la inclusión nos presenta, en primera instancia, un cambio aparente en la concepción de la diferencia, pero al observarlo en detalle, lo que encontramos es que las implicaciones de la inclusión se fundan en una lógica estructural que implica la exclusión. Podría decirse que inclusión y exclusión son indisociables. Por lo tanto, cuando abordamos problemas como los de la inclusión en la educación superior, es necesario comprender la lógica implícita de la inclusión. Su comportamiento topológico y los efectos sobre la diferencia.

Este recorrido presenta un análisis de la inclusión desde la topología a partir de diferentes vértices. Primero desde el cuadrante Pierce, veremos allí como entran en juego las preposiciones universales (afirmativas y negativas) con las preposiciones particulares (afirmativas y negativas) y la consecuencia que tiene esto para el abordaje de la diferencia. Este abordaje se realiza desde la lectura que hace Lacan de la lógica de Pierce. Segundo desde el concepto de homo sacer de Agamben, que permite observar como el principio que subyace a la organización de los estados modernos y los derechos humanos, desembocan en el principio de exclusión-incluyente que tiene como consecuencia la violencia sobre los semejantes. Tercer elemento: la biopolítica como el efecto de la universalización de la pura vida, que permite comprender el papel de la universidad en la inclusión desde la teoría del capital humano. Veremos como la inclusión educativa se convierte en un imperativo que no solo cosifica lo humano como valor, sino que además obliga a modificar las instituciones sociales, en función del principio de inversión, ingreso y capital. Es lo que conocemos como neoliberalismo. Finalmente, el cuarto elemento, muestra una mutación en el discurso universitario, en donde claramente el sujeto comienza a ser comprendido como unidad de valor.

\section{Metodología}

Primer abordaje topológico: Lacan (Seminario 9 inédito) retoma el cuadrante de Pierce para referirse a la identificación.

Lacan presenta la lógica aristotélica en el seminario IX mediante el cuadrante de Pierce, a partir de los enunciados:
a. Todo trazo es vertical
b. Ningún trazo es vertical
c. Algún trazo es vertical
d. Algún trazo no es vertical

Retomemos estos enunciados en función de la igualdad, como principio que sostiene la inclusión. Los enunciados quedarán formulados así:
a. Todos los humanos son iguales
b. Ningún humano es igual 
c. Algunos humanos son iguales (no todos los humanos son iguales)

d. Algunos humanos no son iguales (No hay ningún humano que no sea igual)

Lo que demuestra Pierce es que el atributo es el que define el objeto. Así las cosas, un trazo se define por su condición de ser vertical. ¿Qué quiere decir esto? Que si un trazo no cumple con la condición de ser vertical, sencillamente no puede ser considerado un trazo. Ubiquemos esto mismo en relación con la igualdad. Si un humano se define por su condición de ser igual a otro, entonces un humano que no sea igual no puede ser considerado humano. Esto en el campo de los universales. La inclusión se organiza desde el atributo de la igualdad, por cuanto considera que un humano, por el hecho de tener la vida es igual a otro. Así las cosas, la inclusión obliga a que aquel que es incluido lo haga a costa de definirse igual a otro. Como vemos la diferencia no tiene lugar allí, pues si alguien quiere situar su diferencia en el campo de los universales, entonces pierde su condición de humanidad.

Planteemos ahora la cuestión a partir de la manera como la retoma Lacan: afirma que hay más idea en un objeto concebido como no existente que en su contrario. Retomemos la afirmación negativa: ningún ser humano es igual. En efecto la idea de plantearse un objeto no existente obliga a retomar la representación del objeto existente que representa al mismo tiempo la exclusión de ese objeto. Esto es evidente en el cuadrante de Pierce, porque allí en el lugar de la negación universal: ningún trazo es vertical no hay ningún trazo, simplemente no hay trazo. ¿Qué quiere decir esto? que la negación universal simplemente confirma la afirmación universal. Es decir, el campo de la diferencia, entendida en la afirmación ningún ser humano es igual, obliga a representarse la afirmación todos los seres humanos son iguales. ¿Cuál es la consecuencia? En esta manera de representarse, adviene al mismo tiempo la exclusión de la diferencia. Podemos concluir entonces que la inclusión es la manera de representarse la exclusión. ¿Exclusión de qué? De la diferencia.

¿Quiere decir esto que el asunto de la diferencia no puede ser concebido? No, simplemente, que no puede ser tomado desde el orden de la lexis, es decir desde la universalidad, sino que debe comprenderse desde la particularidad, la phasis, dice Lacan. En la particularidad, encontramos un campo afirmativo en donde pueden haber trazos verticales. Hay también trazos no verticales, pues la afirmación indica: algunos trazos son verticales, lo que quiere decir que otros no lo son. Es lo que viene a soportase en el cuarto sector, la afirmación: Algunos trazos no son verticales. ¿Qué quiere decir esto? que no en todos los casos los trazos son verticales. En nuestras afirmaciones diríamos que no en todos los casos los hombres son iguales.

Retomemos entonces el asunto de la diferencia, que es aquello que realmente debería ser pensado en relación con la inclusión. Esto implica, por su parte, no hablar más de inclusión. ¿Qué es aquello que sitúa la diferencia según Lacan? El rasgo unario, ese es el concepto que sitúa la diferencia radical. El rasgo unario es en efecto un trazo, una marca, que viene del Otro, pero que se instala como una forma particular de goce en cada sujeto. En esa medida, la diferencia que sitúo no es una diferencia que pueda organizar conjuntos o clasificaciones, sino la diferencia radical del sujeto. Esto implica a nivel del discurso sobre la inclusión, que no se puede armar conjuntos con etiquetas para abordar la diferencia. El rasgo unario, no es una marca pasiva en el sujeto, es algo que moviliza toda su búsqueda, y que lo lleva a tratar de repetir esta primera experiencia de la marca. Es por eso que un sujeto ser organiza desde la estructura, porque es desde allí que intenta reencontrar este primer trazo. Por esa razón el abordaje de la diferencia debe realizarse en la estructura misma, es decir en el discurso en el cual el sujeto se inscribe. 


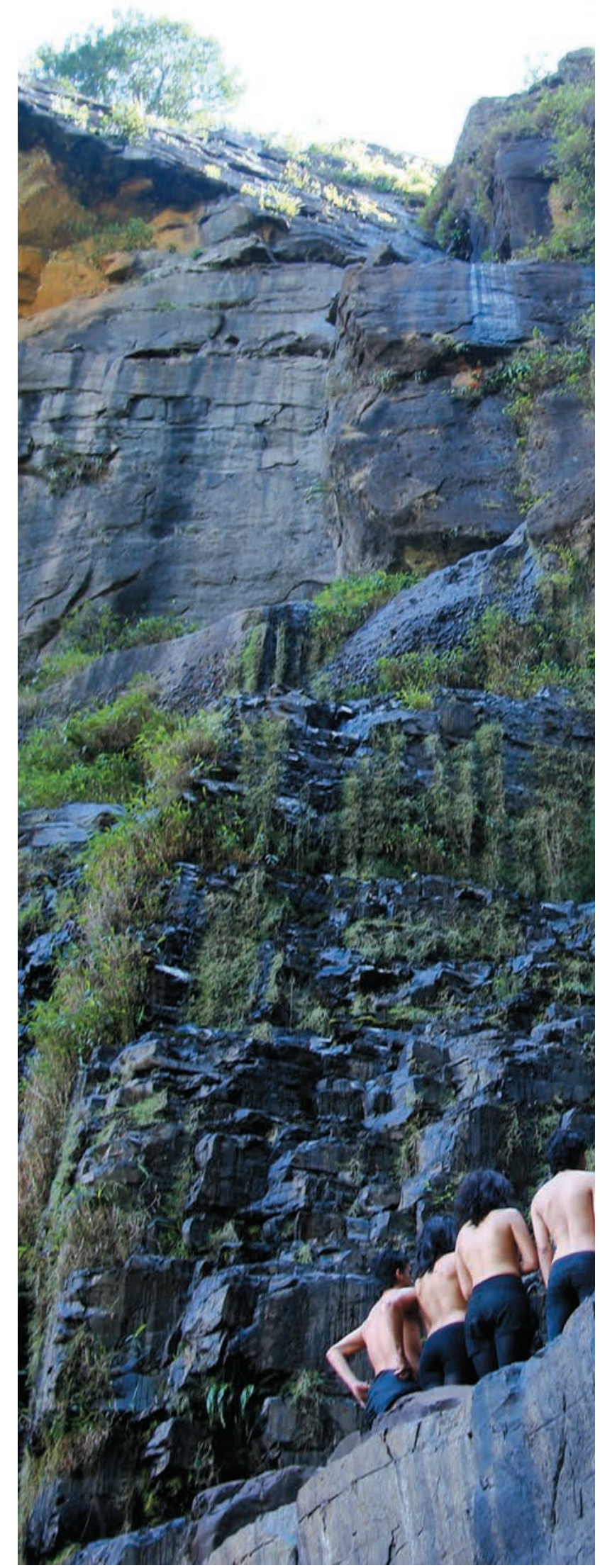

Ahora bien, la estructura es, podríamos decir, un mal necesario para la inscripción del sujeto. Pero no en el sentido de la inclusión, sino en la exclusión que la funda, pues toda agrupación se funda sobre una característica que la exceptúa de otro gran conjunto. Esta es la lógica estructural que sobre la cual se organiza el sujeto. Se agrupa, justamente a condición de exceptuarse a partir de un rasgo.

Si retomamos el cuadrante de Pierce ien qué lugar queda situado el sujeto en esta lógica? Lacan va a decir: en el cuadrante superior derecho. El sujeto es la ausencia de trazo. ¿En dónde queda para nosotros el sujeto de la inclusión? Fuera de ella misma él es la afirmación: ningún ser humano es igual. Pero como él es expresión de un trazo, entonces para inscribirse decreta que hay una clase en donde no puede haber ausencia de trazo. Esta es la particular afirmativa, que adviene como negación de la negación. Entonces se representa a través de esta negatividad que es la afirmación negativa: Algunos trazos no son verticales, lo que quiere decir: no hay ningún trazo que no sea vertical. $\mathrm{O}$ en nuestra afirmación: No hay ningún ser humano que no sea igual. Por efecto de la exclusión estructural, termina anticipándose. Lo interesante de esto, es que es gracias a esta exclusión estructural, que el sujeto logra ordenarse, situarse. Pero esta organización se inscribe como pregunta ¿Podría ser que no haya vertical? ¿Podría ser que no haya iguales? Ese campo de exclusión constituye entonces la búsqueda del sujeto. Esa exclusión constituye lo que el psicoanálisis denomina forclusión. Elemento necesario para que haya movimiento subjetivo. Es decir, la exclusión del sujeto constituye su búsqueda. ¿Qué ocurre entonces con un discurso sobre la inclusión ubicado desde el concepto de la pura vida? La búsqueda queda obturada.

Segundo abordaje topológico: Agamben (2010) retoma el concepto de Homo Sacer para explicar la existencia reducida a la nuda vida. 
La tesis de Agamben tiene que ver con los cambios de la vida moderna, en donde la vida natural comienza a ser incluida en los cálculos del poder estatal, y por lo tanto la política adviene como biopolítica. Se trata entonces de un momento en donde el individuo como cuerpo viviente se convierte en objeto de las estrategias políticas. Observemos entonces que la inclusión es el movimiento mismo de la modernidad hacia el apresamiento de la vida como potencia de organización del poder político. La inclusión no es entonces un movimiento nuevo en la política contemporánea, es, por el contrario, el espíritu mismo de la modernidad. Esto permitió como lo muestra Foucault el paso del Estado territorial al de población. ¿Pero cuáles son las consecuencias de esto? Según Agamben, el efecto de esto es que al mismo tiempo que se instala un mecanismo para proteger la vida, se deja un campo abierto para autorizar el holocausto. "Al situar la vida biológica en el centro de sus cálculos, el Estado moderno no hace más que sacar el vínculo secreto que une el poder con la nuda vida" (Agamben, 2010, p.16)

La tesis central de Agamben (2010) es que la política occidental se organiza gracias a una exclusión que es una implicación, diríamos exclusión-incluyente. ¿Qué es aquello que queda a la vez excluido e implicado? Lo que denomina Agamben (2010) la nuda vida. Es aquello que debe ser incluido por medio de una exclusión. Toda inclusión entonces, motivada desde la política contiene este trasfondo y se organiza sobre este objeto fundamental. La inclusión de la discapacidad no se ubica en otro lugar, el discapacitado es incluido a costa de ingresar como pura vida. Por eso va a concluir Agamben (2010) que la nuda vida es "aquello sobre cuya exclusión se funda la ciudad de los hombres" (p.17) Esa es entonces la potencia de la organización política, por ello concluye que "hay política porque el hombre es el ser vivo que, en el lenguaje, separa la propia nuda vida y la opone a sí mismo, y, al mismo tiempo, se mantiene en relación con ella en una exclusión inclusiva." (p.18)

La paradoja aquí se presenta una vez en la democracia moderna, parecen eliminarse los poderes disciplinarios sobre la vida como objeto, mientras que el sujeto aparece en la esfera como aquel que detenta la posibilidad de elegir. Pero lo que ha ocurrido en esta implicación, es decir, en el hecho que de ser objeto de la política el ciudadano haya pasado a ser sujeto político, es que en este paso, la nuda vida queda exceptuada del ordenamiento y al mismo tiempo es la potencia sobre la cual se despliega la política. Se trata de algo que es incluido en su exclusión. Hablemos del caso de la inclusión social o educativa. El hecho de que alguien sea incluido requiere que su nuda vida quede apresada en esta lógica.

Para explicar esto Agamben se sirve del concepto de Homo Sacer. Concepto que al mismo tiempo que sanciona la sacralidad de una persona, autoriza que se le mate sin que esto constituya un delito. ¿Cómo es que esta doble condición llego a residir en la persona de cada uno? Para adelantarnos un poco, los derechos humanos, que consagran la vida son indicio de ello. La vida es sagrada, por lo tanto insacrificable. No obstante puede darse muerte a un grupo humano, sin que ello constituya un delito, a condición de que se actúe desde el principio de soberanía. Lo que encontramos en esta definición de Agamben es una coincidencia con el Tabú, que señala también algo que es digno de veneración pero que suscita horror. Lo que muestra a este nivel es que las nociones de Tabú y santidad se rozan con frecuencia. Una zona en donde lo puro y lo impuro no son géneros separados, sino dos elementos que componen lo sagrado

A El Homo Sacer presenta entonces una doble excepción: pertenece al dios en la forma de insacrificabilidad (primera excepción) y está incluido en la comunidad en la forma de que se le dé muerte violenta (segunda). Esta potencia 
reside en la soberanía, y es lo que va a entrar a mostrar Agamben (2010), planteando en principio que "Soberana es la esfera en que se puede matar sin cometer homicidio y sin celebrar un sacrificio, y sagrada... es la vida que ha quedado prendida en esta esfera" (p.109) Pensemos por ejemplo en la soberanía del monarca. (Esto puede observarse con detalle en los dos cuerpos del Rey). El poder que lo inviste lo autoriza para dar muerte sin que esto constituya un delito, pues ante el soberano todos los hombres son sacrificables. Vayamos ahora a la soberanía en el Estado de derecho ¿En quien reside? En el pueblo. Así como el soberano, ahora el pueblo está expuesto a la muerte, y puede dar muerte, siempre y cuando se evoque su soberanía.

"La sacrificabilidad de la vida, que hoy se pretende hacer valer frente al poder soberano como un derecho humano fundamental en todos los sentidos, expresa, por el contrario, en su propio origen la sujeción de la vida a un poder de muerte, su irreparable exposición a la relación de abandono."(Agamben, 2010, p.109)

Hay dos conceptos que se enlazan en la ciudadanía contemporánea: soberano, como aquel respecto al cual todos los hombres pueden ser sacrificados y Homo Sacer, como aquel sobre el cual todos los hombres actúan como soberanos. Es decir, constituye el matable, por cuando asesinarlo no implica un delito. Así las cosas, el ciudadano actual encarna a los dos: el soberano y el Homo-Sacer. De un lado es soberano, por cuanto hace parte del pueblo ¿qué poder le otorga esta ciudadanía? El derecho de muerte. Pero por otro lado el es Homo-Sacer para los demás, o sea aquel sobre el cual cualquier otro hombre puede ejercer soberanía. ¿Pero que lo ha hecho Homo Sacer? El hecho de que la vida sea el pivote sobre el cual se articula toda la política, por cuanto la humanidad la constituye el solo hecho de tener la vida. Pensemos en la inclusión. ¿Qué sostiene todo el andamiaje de ese discurso? Una y la misma cuestión: los derechos humanos, comienzo y fin de la inclusión, todo aquello que se diga sobre la inclusión no tiene otro referente: ¿Por qué los seres humanos deben ser incluidos? Porque el hecho de que sean humanos está definido por un atributo: la igualdad. O sea que al tiempo que la vida es incluida en el ordenamiento jurídico, es excluida, por cuanto se convierte en el referente de la decisión soberana, es decir, es aquello frente a lo cual el soberano puede ejercer su soberanía. En esa vía concluye Agamben (2010) que

"la sacralidad es, más bien, la forma originaria de la implicación de la nuda vida en el orden jurídico-político y el sintagma homo sacer designa algo como la relación política originaria, es decir, la vida en cuanto, en la exclusión inclusiva, actúa como referente de la decisión soberana." (p.111)

La vida ingresa en la ciudad bajo una doble excepción: puede matársele impunemente y es insacrificable, en eso puede resumirse la explicación topológica de Agamben (2010), y eso es suficiente para dar cuenta de que el discurso de inclusión es un discurso que se basa en el principio de la vida como derecho humano. Es en función de esto que alguien debe ser incluido en tanto en el ordenamiento jurídico como en las instituciones. Pero es también por ello que sufre el efecto de la inclusión de la pura vida: la exclusión misma. El poder ha recaído sobre esa vida que por allí ha ingresado. Aquel que ingresa en este ordenamiento, es decir, aquel incluido a partir del principio de que su vida es sagrada ingresa como una estatua viviente, según Agamben (2010), pues el hecho de que sea insacrificable es incompatible con el mundo humano. Por eso Agamben (2010) concluye que:"nos encontramos ante una nuda vida residual e irreductible, que debe ser excluida y expuesta a la muerte como tal, sin que ningún rito o ningún sacrificio puedan rescatarla." (p.131) ¿Pero quién ingresa en esta lógica? Todos, en tanto los derechos fundamentales son inalienables. A condición de esto cada uno es para el otro muda vida y al mismo tiempo hombre sa- 
grado. La pregunta aquí es: ¿Si esto es algo que ocurre con todos, porque plantearlo para aquellos que se plantea deben ser incluidos en las distintas dinámicas sociales? Quizá por una razón especial. Ellos eran los que de algún modo habían estado en los márgenes, y por eso eran considerados como marginales. No es que esta condición los mantuviera realmente al margen del biopoder, pues por el contrario, el discurso de la marginalidad obedece ya a una lógica de la inclusión que utiliza el encierro como forma de inclusión. Sin embargo podían mantenerse en un lugar desde el cual cuestionaban por su pura ubicación, el discurso social. Podría decirse que la inclusión, desaparece, al menos en lo evidente esta contradicción.

Tercer abordaje topológico: Foucault retoma la teoría del capital humano para explicar el anclaje de la biopolítica en la sociedad contemporánea

El capital humano es un concepto que retoma Foucault (2007) de los primeros teóricos del neoliberalismo, y que desarrolla en la clase del 14 de marzo de 1979. La teoría del capital humano va a permitir dos elementos: el análisis del capital en un dominio inesperado, y la reinterpretación en términos nada más que económicos, de algo que no se consideraba económico.

Lo que aparece aquí, según el análisis de Foucault (2007), es la posibilidad de analizar el tercer factor de la producción, el cuál apenas había quedado enunciado en la economía clásica, y se había dejado como página en blanco: el trabajo. Desde luego el trabajo había sido tema central del análisis marxista, pero fundamentalmente desde la lógica del tiempo. Lo que observa Foucault (2007) es que con la teoría del capital humano, aparece otra lógica en la comprensión del trabajo.

Se detiene por ello en el análisis de Marx sobre el trabajo. ¿De qué se trata allí? De alguien que vende su fuerza de trabajo a cambio de

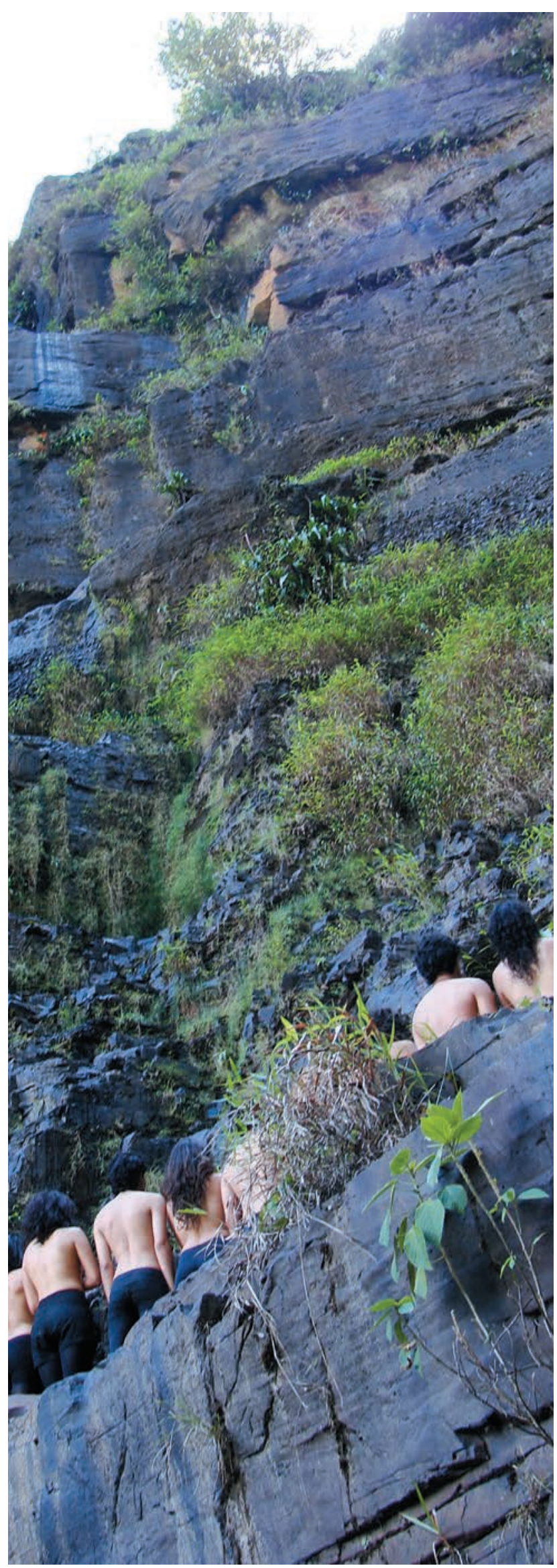




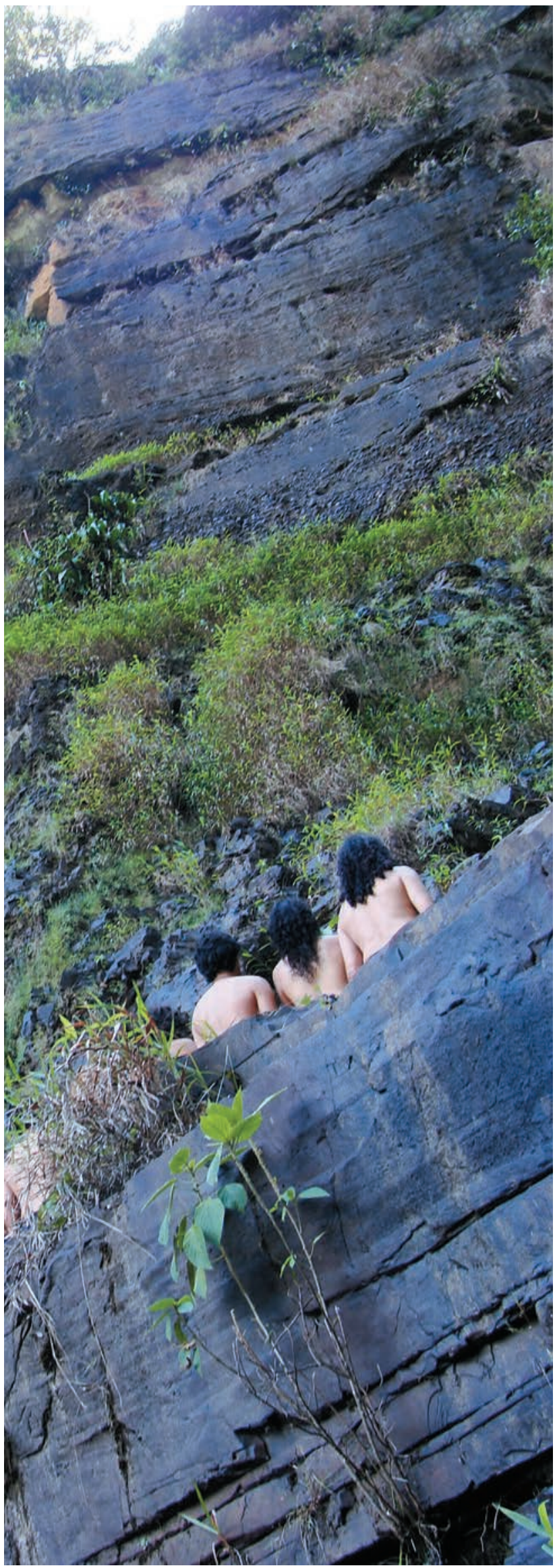

un salario, que sabemos no paga por completo el tiempo empleado en la elaboración de la mercancía. Pero este, dice Foucault (2007), es el trabajo abstracto, medido por el tiempo, no el trabajo concreto. Es un trabajo "amputado de la realidad humana" (p.258). La lógica del capital solo retiene el tiempo y la fuerza. "Hace de él un producto de mercado y sólo rescata los efectos del valor producido" (p.259). Este es el punto en el que los neoliberales se distancian de la explicación marxista, para Marx, la culpa es del capitalismo, mientras que para los neoliberales esto responde a la teórica clásica del capital, pero no al capitalismo. El problema para ellos está entonces en la abstracción teórica que se realizó del trabajo.

Al incursionar en el campo del trabajo y de su relación con los bienes escasos, los neoliberales terminan formulando como principio de la economía lo siguiente: "La economía es la ciencia del comportamiento humano como una relación entre fines y medios escasos que tienen usos que se excluyen mutuamente" (Foucault, 2007, p.260). A partir de ese momento, la economía se ha desanclado de los procesos abstractos de producción, a saber: producción, intercambio, consumo, para insertarse en el análisis del comportamiento humano y su racionalidad interna. "El análisis debe tratar de desentrañar cual ha sido el cálculo - que por otra parte puede ser irrazonable, ciego, insuficiente-, por el cual habida cuenta de la escasez de recursos, uno o más individuos han decidido destinarlos a tal fin y no a otro." (Foucault, 2007, p.261) En adelante la economía será entonces el análisis de la programación estratégica, de la acción de los individuos. En virtud de esto, el análisis del trabajo en la economía no se dirigirá más hacia la comprensión del capital y la producción, el punto fundamental ahora es "Cómo utiliza el trabajador los recursos de que dispone". (p.261). Para entender el trabajo habrá que introducirse ahora en el lugar de aquel que trabaja, es decir, como conducta económica practicada, racionalizada y calculada por 
quien trabaja. “Qué significa trabajar para el que trabaja" "a que sistema de decisiones, a qué sistema de racionalidad obedece esta actividad laboral?" (261). Dice Foucault (2007) que a partir de este momento se introduce un principio cualitativo en la concepción del trabajo, que busca observar como las diferencias cualitativas tienen un efecto de tipo económico.

Al desanclarse el trabajo de la mirada objetiva, la pregunta que retorna sobre el trabajador respecto a su trabajo tendrá una respuesta distinta. Ya no se trata de que el trabajo sea el precio de venta de su fuerza de trabajo. Para él se trata de un ingreso. Y es allí cuando los neoliberales van sobre el significado de este, pueden anclar el trabajo en la lógica del ingreso, es decir como "el producto o rendimiento de un capital" (Foucault, 2007, p.262). Si el capital es todo aquello que puede ser fuente de ingresos futuros entonces capital e ingresos se han amalgamado en un concepto capital humano. Se trata de un capital cuya renta es el salario, y que Foucault (2007) define como "el conjunto de factores físicos, psicológicos, que otorgan a alguien la capacidad de ganar tal o cual salario" (p.262). Desde la óptica del trabajador, el trabajo es un capital, una aptitud, una idoneidad, por lo que concluye Foucault: es una máquina.

Pero este no es un capital como cualquier otro, pues es un capital indisociable de aquel que lo posee. "La idoneidad que se hace carne en el trabajador es... el aspecto en que este es una máquina, pero una máquina en el sentido positivo, pues va a producir flujos de ingresos". (Foucault, 2007, p.263) Esto le permite a Foucault agregar que por ello está máquina tiene su vida útil y su periodo de obsolescencia. Ahora entonces el trabajador es una empresa para sí mismo. "Una economía hecha de unidadesempresa" (Foucault, 2007, p.264) El argumento central de Foucault es pues, y creo que esto lo resume todo: "el neoliberalismo aparece... como el retorno al homo-económicus" (p.264). Es el socio del intercambio, el empresario de sí mismo, y por eso debe descomponerse en términos de utilidad y de comportamiento. Al ser su propio socio, el empresario de sí mismo debe hacerse cargo de su producción, de su capital, fuente de sus ingresos. Vemos aquí emerger lo que solapada e ingenuamente aparece como teoría del liderazgo, técnicas de autosuperación, y en fin, todo lo que puede producirse del cruce entre la economía y la psicología en su vertiente administrativa.

Ahora de lo que se trata es de la administración de sí mismo, con miras al logro de la utilidad producida por el capital, capital humano, capital que es cada uno. Lo que se imbrica aquí es aquello que intentó Marx objetivizar al decir que el consumo es la producción, y lo advierte Foucault (2007) al decir que el hombre de consumo es un productor, produce su propia satisfacción. "El consumo debe considerarse como una actividad de empresa por la cual el individuo, precisamente sobre la base de un capital determinado del que dispone, producirá algo que va a ser su propia satisfacción." (2007, p. 265)

Ahora el punto es entender cómo está compuesto el capital humano. Foucault (2007) se lo pregunta, y retoma la idea según la cual está compuesto de material innato y adquirido. En los primeros encontramos los hereditarios y los congénitos. Sobre esto, la apuesta queda en manos de la genética y todos los efectos que pueda tener en el mejoramiento del capital humano. Sobre lo segundo, el elemento central para obtener un capital humano que produzca ingresos, es la inversión. Debe invertirse en el capital humano si queremos que produzca ingresos. Foucault lo dice de manera más precisa cuando se pregunta qué quiere decir formar capital humano, su respuesta es: hay que realizar una inversión educativa. He ahí la repuesta a la inclusión en nuestros días, se trata nada más que de una inversión en capital humano. Tenemos dos vías privilegiadas para ello: la instrucción y la formación profesional. Esto se traduce hoy, para ser más precisos, en lo que desde el discurso universitario denominamos: 
Formación permanente. Pero esto se traduce también en una serie de discursos legitimados desde la ciencia, que dicen por ejemplo que es necesaria la presencia de la madre en los primeros meses de vida del infante, para que este logre un pleno desarrollo. Este tiempo de los padres destinado a la lactancia, al cuidado de sus crías, debe entenderse entonces, tal cual lo hace notar Foucault como una inversión para constituir un capital humano. Allí se juegan otros factores, como la cultura de los padres, que se traducirá en capital cultural, la estimulación temprana, los entornos. En eso mismo se traducirán entonces las atenciones médicas, y todas las actividades concernientes a la salud. Se trata de un asunto de racionalidad utilitaria. A lo que invita Foucault (2007) aquí es entonces a pensarse todos los problemas de la educación y la salud desde está lógica: se trata de una inversión en el capital humano.

En la teoría del capital humano, la innovación juega un papel fundamental, sobre esto se detiene Foucault, a partir de las formulaciones de Schumpeter, quien afirma que la ganancia depende de la innovación tecnológica, del descubrimiento de nuevos mercados y nuevos recursos de mano de obra. Lo que se han descubierto aquí son nuevas formas de productividad, todo lo cual radica en el capital humano. Así las cosas, al ser este uno de los factores fundamentales de la productividad, es necesario encaminar las políticas económicas, sociales, culturales y educacionales. ¿No es esta la lógica en la que se sitúa la inclusión desde la perspectiva de las instituciones y los marcos jurídicos? ¿Por qué existe un marcado interés de diversos sectores, y sobre todo de la educación por abrir sus puertas a la inclusión? Su lógica como vemos obedece básicamente a una racionalidad económica. Racionalidad en la que nos vemos envueltos todos: Para las instituciones se tratará fundamentalmente de producir estos capitales rentables. Para el sujeto se tratará de invertir en su capacidad adquisitiva. En síntesis, de lo que se trata es de generar unidades de valor, capital humano.

\section{¿ La univerdidad es excluyente?}

¿En qué momento la universidad ingresa en la lógica del capital humano?

En primer lugar es necesario entender la Universidad como un discurso. Al ser un discurso organizado desde el saber, es en principio un discurso universalizante, busca por un lado la universialización del conocimiento, es decir, encontrar verdades y leyes generales. Por otro lado quien ingresa en este discurso, deberá aprehender bajo premisas universalizantes y despojándose de la perspectiva singular. Esto implica que lo que produce este discurso, pues todo discurso produce algo, es un sujeto. Pero para producirlo este debe ingresar primero como objeto. En el ejercicio de la Universalización la universidad es excluyente. Esto implica como premisa básica, que todo aquel que ingresa en el discurso universitario, es decir, todo aquel que es incluido en sus enunciados, queda sometido a una exclusión estructural, la exclusión de la singularidad. Bajo el principio de igualdad, en el sentido de sus presupuestos universales, la singularidad queda desprovista del proceso educativo. No obstante, en principio la universidad es excluyente, pues únicamente ingresan aquellos quienes son considerados aptos para pasar por el dispositivo de enseñanza, y que deben tener unas capacidades específicas, por eso se considera que es excluyente, pero aquí, en el sentido del acceso. Ahora bien, ¿Qué ocurre con la inclusión educativa? ¿Qué implicaciones tiene que un discurso aparezca para decir que ahora todos deben ser incluidos en la institución universitaria? ¿Bajo qué presupuesto aparece la inclusión educativa?

En Vincennes Lacan (1999) afirmó que el objeto $a$ en la Universidad señala la objetividad, es decir que cada uno es puesto allí, en el lugar del objeto para taponar el agujero, razón por la cual son "proyectados objetos de esperanza," y es por esto que en la objetivación, cada uno ha tomado cuerpo convirtiéndose en unidad de valor. Por eso recordó a los estudiantes de Vin- 
cennes que las unidades de valor van cambiando de valor de uso al valor de cambio, y que por eso "ustedes están predestinados en esta pequeña mecánica, más allá de lo que quieran, a jugar el mismo rol que todo lo que hay de objeto a en la sociedad capitalista, a saber, funcionar como plus-valía." (Lacan, 1999, p.17) $Y$ agrega que son verdaderos valores en tanto van a sostener el modo de intercambio de la sociedad capitalista, algo que hoy se denomina capital intelectual, y apunta a una era del conocimiento.

Lo que se les demanda producir desde este lugar a los estudiantes, es cultura, "promoción cultural de la sociedad", por lo que Lacan (1999) señala que lo que se les demanda está en un lugar que es del Otro. $Y$ es por eso que existe una dificultad para cuestionar el sistema desde este lugar, porque "en la medida que ustedes puedan producir algunos agradables balbuceos, ustedes alimenta al sistema." (Lacan, 1999, p. 19)

Ese cambio, que en Francia se venía situando desde el 68, sitúa la lógica en la que luego va a terminar organizándose la inclusión educativa. Si la Universidad ha abierto las puertas a la inclusión, es porque es menester formar el capital humano, bajo el principio de la igualdad. Sabemos que está igualdad se basa en el principio de la pura vida, en cuanto está sustentada a partir de los derechos humanos. Pero de otro lado tenemos los intereses de aquello que piden que las puertas se abran para ser incluidos en las instituciones educativas. Sus razones obedecen a lo mismo: ellos requieren gestionar su empresa que son ellos mismos, ellos requieren mejorar sus ingresos, ellos se han identificado con el capital humano. Ellos son capital humano. Vemos emerger entonces la exclusión desde este último ángulo, aquella que plantea el valor. Sabemos que el valor de cambio constituye la exclusión por excelencia del capital, en cuanto se trata de algo que para obtener su valor de cambio debe ser objetivado. El tiempo es el elemento que permite esta objetivación y

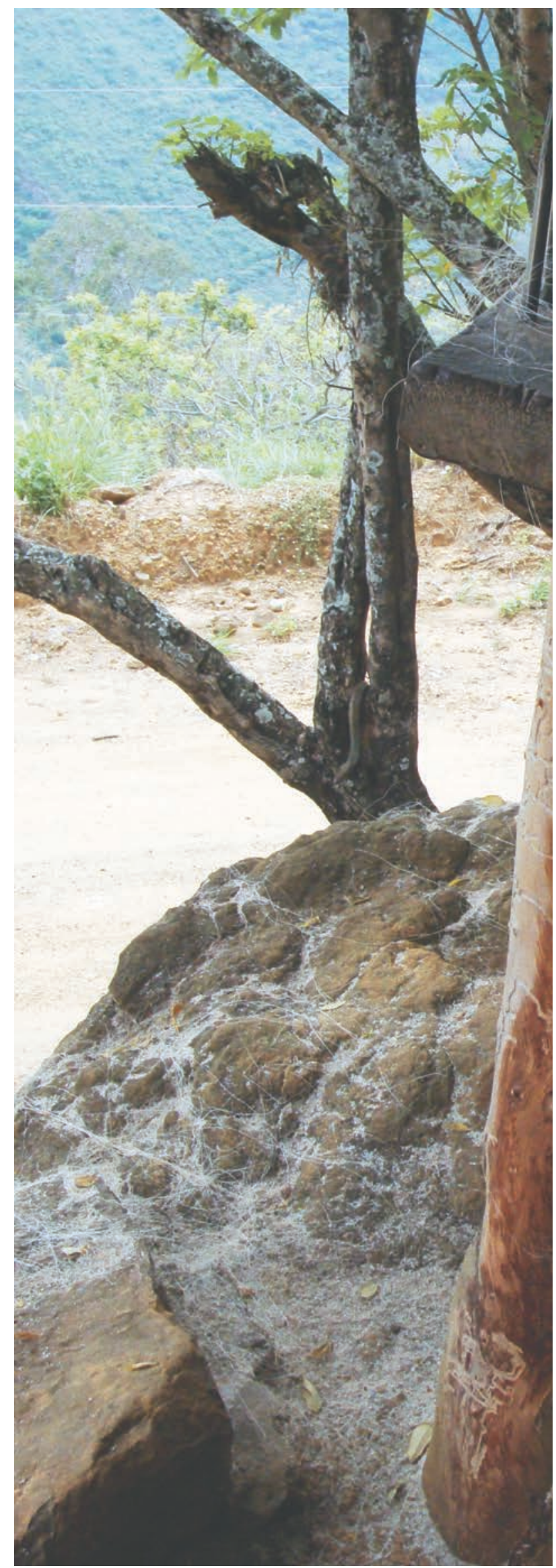


que se traduce en dinero, el dinero es la representación de este tiempo de trabajo. Pero Foucault ha mostrado como el patrón de definición del trabajo se ha transformado, ya no es el tiempo de trabajo, ahora es el capital humano. ¿Qué implica esto? Que la unidad de valor ha variado, ahora la unidad de valor es cada uno. Así, la inclusión en la universidad implica que se ingresa como unidad de valor y se sale como unidad de valor, traducida en capital humano.

\section{Conclusiones}

En este sentido, la inclusión es una cuestión de inversión en capital humano. Por más que se disfrace el discurso de la inclusión con las vestiduras de la filantropía y el humanismo la consecuencia es la misma. Del lado del humanismo el efecto es la exclusión de la diferencia. Del lado de la economía el resultado es la inclusión de su cuerpo como unidad de valor. El abordaje topológico de la inclusión permite entonces observar la lógica estructural que subyace al discurso moderno de la inclusión.

Cada cual deberá definir su lugar dentro de esta lógica, independientemente de cómo se defina la humanidad y más aún si es la definición moderna: como pura vida, de ahí que los tres tiempos lógicos que introduce Lacan (2002):
1. Un hombre sabe lo que no es un hombre

2. Los hombres se reconocen entre ellos por ser hombres

3. Yo afirmo ser un hombre, por temor a que los hombres me convenzan de no ser un hombre.

Esta anticipación marca su lugar en la exclusión-incluyente. Sin importar las consecuencias de inscribirse como Homo - Sacer, prefiere ser incluido en este. Ya que lo sitúa en la enunciación como único lugar posible, para quedar luego excluido en tanto que es pura vida. Hombre sagrado y, por lo tanto, aquel que puede ser asesinado impunemente.

\section{Referencias}

Agamben, G. (2010) Un poder soberano y la nuda vida I. Valencia: Pre-Textos.

Foucault, M. (2007) Nacimiento de la Biopolítica. Buenos Aires: Fondo de Cultura Económica

Lacan, J. (Inédito) El seminario 9

Lacan, J. (2002) El tiempo lógico y el aserto de certidumbre anticipada. En Escritos 1. Buenos Aires: Siglo XXI Editores.

Lacan J. (1999) El seminario 17: el reverso del psicoanálisis. Buenos Aires: Paidós. 